\title{
Perceptions of postgraduate trainees in paediatrics on the educational environment at Lady Ridgeway Children's Hospital Colombo
}

\author{
Manouri P Senanayake ${ }^{1}$, Dishni Wijesundere ${ }^{2}$ \\ Sri Lanka Journal of Child Health, 2014; 43(1): 20-22
}

\begin{abstract}
Introduction: The importance of the educational environment /climate is well recognised and believed to affect not only academic progress but also professional behaviour and career commitment. This paper describes the perceptions of postgraduates preparing to sit their exit examination in general paediatrics at Lady Ridgeway Hospital (LRH). This is an important training centre because all paediatricians-in-training in Sri Lanka compulsorily undergo one year of training at this hospital.
\end{abstract}

Objective: To evaluate the perception of postgraduate trainees on the learning environment at LRH

Study design: A cross-sectional, descriptive study

Study sample: Trainees who had undergone nine or more months of training at LRH but had not yet sat the end of course examination

Method: Ethical approval was obtained from Ethics Review Committee of Faculty of Medicine Colombo. This study was carried out in 2009-2010 using the Dundee Ready Education Environment Measure, a validated tool for evaluating an educational environment/climate. Trainees were asked to fill in the 50 statement inventory by responding anonymously on a 5 point Likert-type scoring scale. The instrument measured the personal, interpersonal and organizational domains of their own learning situations in five important aspects of education: perception of learning, perception of course organizers / teachers, perception of atmosphere, academic self-perception and social self-perception.

Results: Number of respondents was 46. Response rate was over $95 \%$. Overall mean score was 104

${ }^{1}$ Senior Professor in Paediatrics, ${ }^{2}$ Research
Assistant, Department of Paediatrics, Faculty of
Medicine, Colombo

(Received on 17 May 2013: Accepted after revision on $26^{\text {th }}$ July 2013) (range 78-158). In the individual subsets academic self-perception and perception of teachers / course organizers were 'more positive than negative' in the majority. Perception of course organizers was viewed negatively by one fifth $(21 \%)$. Social self perception scored the lowest. Sixty seven percent thought with regard to their personal social lives they were in an environment that was "not nice" or "miserable".

Conclusions: Majority of postgraduate trainees perceived the learning environment at LRH positively but $67 \%$ had a negative perception regarding their personal social lives.

(Key words: Perceptions; postgraduate trainees in paediatrics; Dundee Ready Education Environment Measure; DREEM; Lady Ridgeway Hospital, Colombo)

\section{Introduction}

Trainees' perception of the educational environment is recognised to have a significant impact on academic progress, retention of learning, professional behaviour, career commitment and personal wellbeing ${ }^{1,2,3}$. The Lady Ridgeway Hospital (LRH), Colombo, is the premier children's hospital in Sri Lanka and affords a vast array of clinical material and an environment rich in learning opportunities. LRH is a training centre for all postgraduates sitting the exit examination (MD Paediatrics) that leads to specialization. Evaluating the educational climate is of value as it provides a feedback to course organizers and forms a basis for enhancing the quality of training.

\section{Objective}

To evaluate the perception of postgraduate trainees on the learning environment at LRH

\section{Method}

In this cross-sectional, descriptive study, the instrument used was the Dundee Ready Education Environment Measure (DREEM), a validated tool for 
evaluating an educational environment/climate. It contains a five point standardized score scale of fifty statements that cover personal, interpersonal and organizational domains. These are categorized into five important subsets which reflect important aspects of education i.e. perception of learning, perception of teachers, perception of atmosphere, academic self-perception and social self-perception.

Trainees who had undergone at least nine completed months of training at LRH were the study population. Those trainees who were re-sitting the examination were not included. Ethical approval was obtained from the Ethics Review Committee of the Faculty of Medicine, Colombo and the study was carried out in 2009 - 2010. The trainees were free to refuse participation. Trainees were invited to respond honestly and anonymously by filling in the 50 item DREEM and to do so, based on their personal views and experience. DREEM was filled in individually and collected via the internal mail. No names were mentioned in any part of the evaluation. All respondents were competent in English.

\section{Results}

Forty six of forty eight trainees who trained in 2009 and 2010 responded. All the DREEM forms were filled in completely. Highest score was 158. Mean total score was 104. On overall scores, an interpretation of the environment being "excellent" (i.e. a score of $>150$ ) was present in only $5 \%$ of postgraduates. However, the overall perception of the majority $(>78 \%)$ was that the learning environment was "more positive than negative". Within the five subsets there were variations (Table 1). Although majority of postgraduates were positive with regard to 'academic self-perceptions', 'views on teachers / course organizers' was negative in one fifth $(21 \%)$ and in $17 \%$ the scores conveyed that the course organizers needed some retraining. Although attitude to the atmosphere in the hospital was positive in $60 \%$ 'social self-perception' was negative in the majority. Fifty percent of trainees considered the hospital "not a nice place" with reference to their personal social lives and $17 \%$ thought it was "miserable" (Table 1 ).

Table 1: Perceptions of postgraduates as interpreted based on DREEM scores

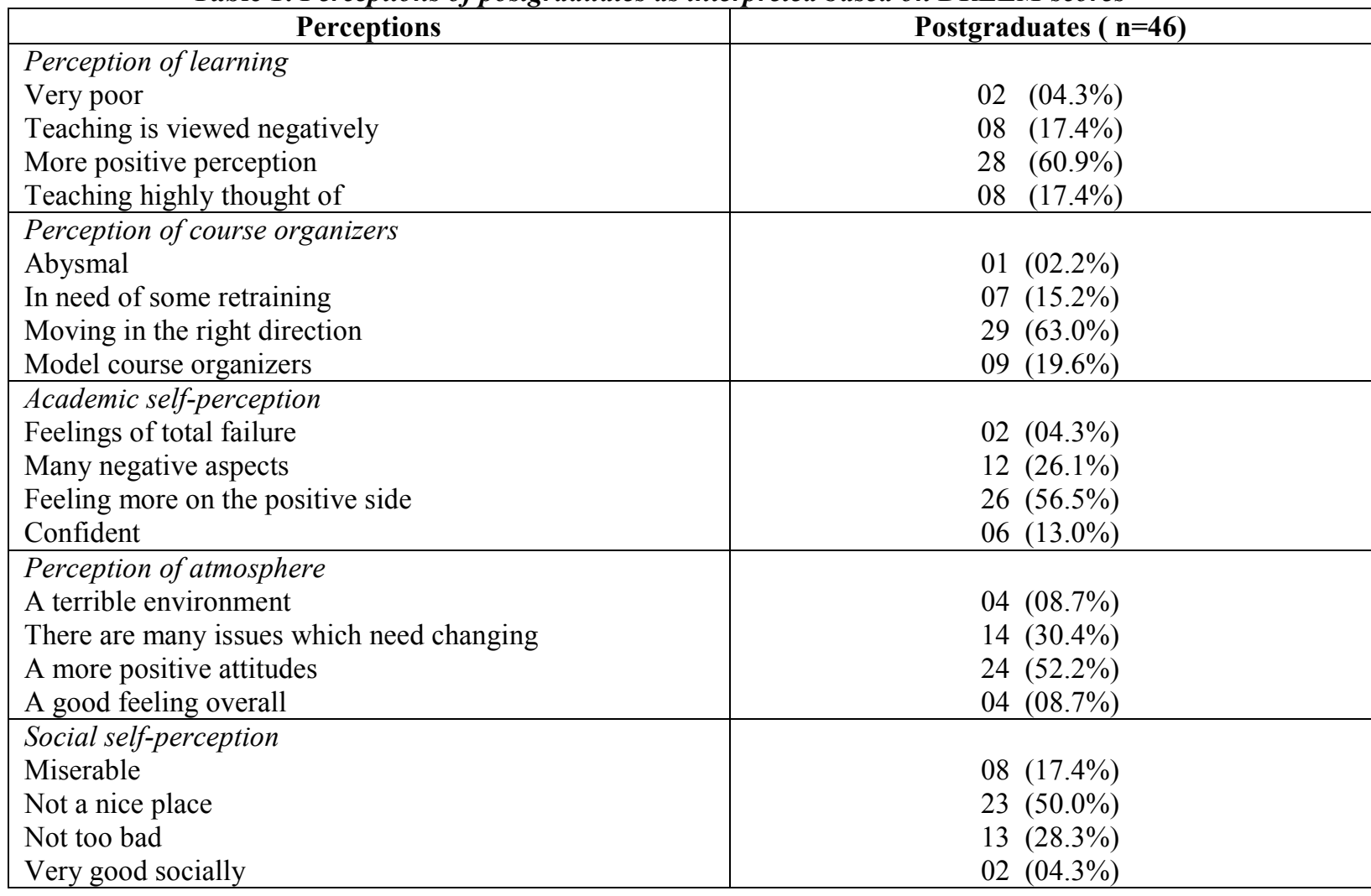

\section{Discussion}

The learning environment plays a crucial role at all levels of training. Although DREEM has been primarily used to assess perceptions of undergraduates, its usefulness in postgraduates and other health professionals has been well documented. It can be used among postgraduates following some 
minor changes to terminology, which we did prior to conducting this study ${ }^{4}$.

This study included postgraduates in general paediatrics, nearing the end of a three year long intensive training period. Although the training programme was structured and supervised, like most postgraduates in clinical disciplines, the respondents were not students in the formal sense. They had service duties with on-call rosters and long working hours. Learning was largely integrated into routine practice. Responsibility for the care of sick children placed directly under them weighed heavily throughout the training period. DREEM included statements on the trainee's personal domain such as leisure and self esteem which were scored lowest in the responses. Work related stress, mounting family commitments and the prospect of having to sit an examination with a possible high failure rate, were expressed as likely contributors to poor social and academic self-perceptions, on follow up discussions with individual postgraduates and with focus groups. In view of the fact that the main drivers of adult learning are self-motivation and relevance (the latter being success at a high stakes examination in this population), these negative perceptions warrant close attention.

\section{Conclusions and recommendations}

More than $78 \%$ of postgraduate trainees had scores indicating that the learning environment at LRH was perceived positively. Sixty seven percent had a negative perception regarding their personal social lives.

We recommend that further studies with same or similar methodologies e.g. PHEEM (Postgraduate Hospital Educational Environment Measure) be undertaken periodically to provide course organizers with a better understanding of the trainee's concerns as well as the strengths and weaknesses of the training institution ${ }^{5}$.

\section{References}

1. Genn JM. Curriculum, environment, climate quality and change in medical education - a unifying perspective. Medical Teacher 2001; 23:445-54. http://dx.doi.org/10.1080/01421590120063330

2. Pimparyon P, Roff S, Mcaleer S, Poonchai B, Pemba S. Educational environment, student approaches to learning and academic achievement in a Thai nursing school. Medical Teacher 2000; 22:359-65. http://dx.doi.org/10.1080/014215900409456

3. Audin K, Davy J, Barkham M. University Quality of Life and Learning (UNIQoLL): an approach to student wellbeing, satisfaction and institutional change. Journal of Further \& Higher Education 2003; 27:365-82. http://dx.doi.org/10.1080/030987703200012807 $\underline{3}$

4. Miles S, Swift L, Leinster SJ. The Dundee Ready Education Environment Measure (DREEM): A review of its adoption and use. Medical Teacher 2012; 9:620-34. http://dx.doi.org/10.3109/0142159X.2012.66862 $\underline{5}$

5. RoffS. Measuring educational and training environments as part of QA. Available from: http://www.medev.ac.uk/newsletter/article/141/ 